\section{Nascimento, vida e morte de uma política pública: uma etnografia do programa De Braços Abertos}

\author{
Birth, life, and death of a public policy: an \\ ethnography of the Open Arms program
}

\author{
Nacimiento, vida y muerte de una política \\ pública: una etnografía del programa \\ De Brazos Abiertos
}

Ygor Diego Delgado Alves 1

Pedro Paulo Gomes Pereira 1

Paulo Sergio Peres 2

doi: 10.1590/0102-311X00213918

\section{Resumo}

Políticas públicas direcionadas à Cracolândia (São Paulo, Brasil) vêm sendo implementadas há décadas e carecem de uma descrição abrangente. Realizamos este estudo pela importância e caráter inovador do programa De Braços Abertos (DBA), com o propósito de oferecer um quadro compreensivo desde seu início até o encerramento. Isso por meio: (i) do levantamento das atividades desenvolvidas por agentes públicos que precederam o Programa e que influenciaram diretamente a sua formulação; (ii) da descrição do estado em que se encontrava a Cracolândia no momento de implantação do DBA; (iii) da especificação dos atores institucionais e suas atribuições; e (iv) da exposição dos principais acontecimentos que marcaram o desenvolvimento dessa politica pública até sua extinção. Para tanto, nos valemos de nossa vivência etnográfica na Cracolândia, que pôde ser cotejada com uma parcela importante do material bibliográfico existente sobre o tema. Identificamos uma forte influência do trabalho pregresso de profissionais, principalmente do campo da Saúde Mental do município na concepção e desenvolvimento do DBA, mas que, no entanto, aconteceu com a participação ativa de diversos entes, com importante caráter intersecretarial. A pesquisa mostrou a relação intima e adaptativa entre o Programa e o ambiente da Cracolândia, assim como os conflitos com o crime organizado e as polícias que fomentaram o desenvolvimento de competências específicas por parte dos agentes do município. Ao ser desmantelado, o Programa deixou uma importante herança no surgimento de uma militância em prol dos direitos recém-adquiridos pelos usuários de crack, o que certamente poderá significar alguma resistência contra medidas do poder público.
Correspondência

Y. D. D. Alves

Universidade Federal de São Paulo.

Rua Botucatu 740, 4o andar, sala 404, São Paulo, SP 04037-002, Brasil.

antropologiaygor@yahoo.com.br

1 Universidade Federal de São Paulo, São Paulo, Brasil. 2 Instituto de Filosofia e Ciências Humanas, Universidade Federal do Rio Grande do Sul, Porto Alegre, Brasil. 


\section{Introdução}

O ciclo das políticas públicas abrange a formação da agenda, a formulação das propostas, a tomada de decisão sobre a política a ser adotada, sua implantação, sua avaliação e sua continuidade ou encerramento 1,2,3,4,5. Todas essas etapas costumam ser analisadas, isolada ou articuladamente, porém, são raros os estudos que acompanham uma política pública desde o seu surgimento até o seu término 6 . Muitas vezes, o grau de especialização dessa área de investigação exige que os pesquisadores se concentrem em apenas um ou dois momentos desse ciclo. Outro impeditivo para a realização de estudos abrangentes é a inexistência ou indisponibilidade de dados referentes a todas as etapas de uma política. Outro limitador é a adoção exclusiva de métodos quantitativos, uma vez que diversos aspectos de partes do ciclo das políticas somente são acessáveis por abordagens qualitativas aprofundadas, que exigem uma prolongada estadia no campo visando a observações sistemáticas.

O objetivo deste artigo é, precisamente, este: analisar, descritivamente, o desenvolvimento histórico do programa De Braços Abertos (DBA), desde sua adoção, em 2014, no Município de São Paulo, Brasil, pela administração do prefeito Fernando Haddad (Partido dos Trabalhadores - PT), até seus últimos dias, em 2017, na gestão de João Dória (Partido da Social Democracia Brasileira - PSDB). Em termos operacionais, o DBA integrou ações intersetoriais das áreas de Assistência Social, Direitos Humanos, Saúde e Trabalho, sob a lógica da redução de danos. Sua meta era a construção de uma rede de serviços destinada ao atendimento social aos usuários de crack, mediante a oferta de moradia, emprego e serviços de atenção integral à saúde. Em função desse desenho institucional e de seu foco inovador, que substituiu a atuação repressiva e terapêutica das políticas anteriores por um programa que não exigia abstinência e que era pautado pela reinserção social dos usuários, por meio da redução de sua condição de vulnerabilidade 7,8 . O DBA teve a pretensão de estabelecer novos parâmetros para o equacionamento de um problema que parece ser uma "aporia urbana”, pois em algumas ações, ao mesmo tempo em que buscam o "fim da Cracolândia”, a trama institucional armada também se alimenta da sua existência e necessita da "contenção da população usuária de crack em um mesmo local para viabilizar o seu trabalho" 8 (p. 21-2).

Desde a entrada do crack no centro de São Paulo e sua instalação na região que, a partir dos anos de 1990, passou a ser chamada de Cracolândia, diversas ações, muitas das quais envolvendo repressão policial, não colocaram fim à área de consumo da droga 8 . Ao contrário, antes conhecida como uma zona de venda da droga, a Cracolândia acabou se convertendo num espaço de consumo intensivo 9,10, que chegou a ter, antes do DBA, um "fluxo" de três mil frequentadores diários.

A partir de então, esse agrupamento urbano foi objeto de pesquisas etnográficas que destacaram, desde as relações entre o Estado, o legal e o ilegal 10,11,12, passando pelas relações entre saúde e ambiente 13, pela territorialidade e suas conexões com a cidade 10,14,15 e as estratégias de autocontrole e autocuidado 11,16, até as práticas de lazer e resistência 17,18. Não obstante, as análises sobre o DBA ainda são escassas 7,8, em especial, uma história mais pormenorizada do Programa. Por isso, consideramos que, ao seguir essa política pública, do seu surgimento até o seu desmantelamento, nossa análise pode contribuir para a composição de um panorama a respeito de como o Programa foi desenhado, dos seus conflitos, da sua trajetória e do papel dos agentes envolvidos e afetados - pessoas, grupos e instituições.

Nossa análise baseia-se numa pesquisa etnográfica de seis anos, realizada junto à população de rua atendida pela política e seus operadores, técnicos e agentes a serviço do poder municipal. Com essa abordagem, assim como fizeram outros pesquisadores das Ciências Sociais, que estudaram as políticas públicas 19,20,21, pudemos observar o desenvolvimento do DBA como um sistema de relações formais e informais, que abriga tanto convergências como incompatibilidades, contradições e tensões 22,23.

\section{Metodologia}

A base empírica deste estudo é uma pesquisa etnográfica iniciada no ano de 2012, na região do centro da cidade de São Paulo, conhecida como Cracolândia. Como amplamente reconhecido desde os primórdios da Antropologia Cultural 24, a prática etnográfica consiste numa pesquisa de campo com observação participante. Ela envolve intensa aproximação com o objeto de estudo e serve-se da observação e de anotação de informações acerca da vida de pessoas capazes de se sentirem suficiente- 
mente confortáveis com a presença e proximidade do pesquisador ${ }^{24}$. Além disso, permite certo tipo de conhecimento experimentado que possibilita uma fala convincente e densa sobre o tema pesquisado 24 .

Convivemos por anos com usuários de crack e profissionais que trabalhavam na Cracolândia, o que nos permitiu realizar dezenas de conversas gravadas - um importante recurso para se obter e armazenar informações cruciais para o entendimento de problema tão complexo. Os diálogos foram inseridos em uma linha do tempo, previamente construída, que acompanhou as notícias veiculadas pela mídia e pela própria Prefeitura de São Paulo, permitindo a convergência das informações etnográficas com as documentais. $\mathrm{O}$ longo processo de observação e convivência permitiu que testemunhássemos a transformação na configuração espacial e social daquele território. Percebemos uma expressiva retração da cena de uso e a inserção dos beneficiários do DBA na rede socioassistencial e de saúde. Acima de tudo, vimos o florescer, o amadurecer e o desmoronar de uma política pública.

\section{A dinâmica histórica do DBA}

\section{Precedentes para a política}

A concepção do DBA foi influenciada por duas experiências anteriores. Uma delas foi o trabalho do Dr. Marcelo Clemente 25 que, ao final da primeira década do século XXI, fazia parte da unidade básica de saúde (UBS) República e participava de reuniões com a Dra. Myres Cavalcanti, do programa de Saúde Mental, da Secretaria Municipal de Saúde (SMS). A atuação do Dr. Clemente era diferenciada por sua presença no interior da cena de consumo do crack e, também, por levar em consideração as sugestões dos dependentes em seu trabalho regular. A Dra. Cavalcanti, por sua vez, viria a ser uma das formuladoras e gestoras no DBA e aparece no livro Cracolândia Dia a Dia, do Dr. Marcelo Clemente, como a técnica que, nas reuniões que ambos frequentavam, ficava a par dos acontecimentos na cena de uso e dava instruções.

A outra experiência é a de uma assistente social, Maria Albertina França, ou Dona Tina, que, aos 70 anos de idade, enquanto o DBA dava os seus primeiros passos em 2013, visitava a cena de uso, semanalmente, por vezes sozinha e no período noturno, para abraçar as pessoas. Em entendimentos com a SMS e a Defensoria Pública, a assistente social começou a se reunir com o poder público municipal. Antônio Lancetti, um dos idealizadores do DBA, chegou a acompanhar, em diversas oportunidades, a "terapia do abraço", de Dona Tina, no interior do "fluxo" 26, no cerne da Cracolândia. O nome do projeto de Dona Tina era Aquele Abraço.

Em termos populacionais, ao falarmos dos frequentadores do "fluxo", ou seja, a concentração mais densa de consumidores da droga na Cracolândia, fazemos referência, principalmente, aos moradores de rua, usuários de crack 25 , com um padrão de uso que pode ser considerado compulsivo ${ }^{16}$. Essa delimitação é necessária porque no espaço da Cracolândia circulam pessoas que não fumam crack, assim como aquelas que, por qualquer razão, apenas visitam o lugar. Quanto ao território, procuramos evitar seu aspecto mais negativo de representação 27 , ligado ao horror, à morte 28 e à degradação 29 , de modo a privilegiar a compreensão de sua importância para o exercício da alteridade 15 e da sociabilidade 30. Isso não significa, entretanto, desprezar as situações de vulnerabilidade $31 \mathrm{e}$ as decorrentes do agravamento da questão social 32 ali presentes, mas levar em consideração o papel 33 que o consumo coletivo do crack e do álcool pode ter para a sobrevivência na rua ${ }^{34}$, para a proteção contra o controle policial 35 e para a articulação de demandas sociais 36 .

Em 22 de julho de 2013, o DBA foi pré-iniciado com a instalação de um equipamento municipal na Rua Helvetia, quase esquina com a Alameda Cleveland. Ali foi estabelecido, próximo ao "fluxo", o Ponto de Apoio para dar resposta ao sofrimento causado pelo frio do inverno. Posteriormente, o Ponto de Apoio passou a ser a Tenda do DBA. Seus objetivos principais, no início, eram ser uma espécie de extensão da rua e assegurar que suas decisões administrativas fossem tomadas em assembleias com a participação dos frequentadores.

Ainda antes da implantação do DBA, também foi implantado o Serviço de Assistência Especializada (SAE), localizado na Alameda Cleveland, ao lado do "fluxo" (Figura 1). O SAE contava com equipes de Consultório na Rua, que atuavam naquele território desde pelo menos 2009, e ficou responsável pela assistência ambulatorial às pessoas vivendo com HIV/aids e hepatites virais. 
Figura 1

Assistente social do Serviço de Assistência Especializada (SAE) passa ao lado do "fluxo".

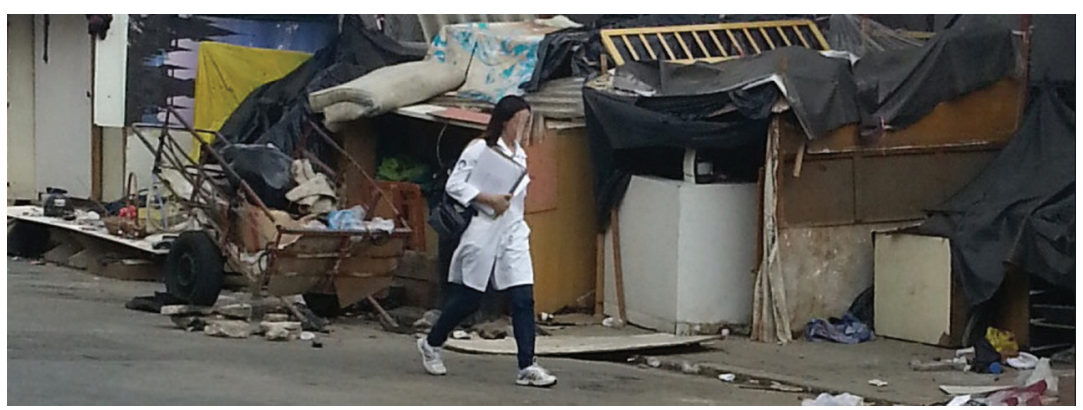

Nota: foto do autor.

Desde 2008, portanto, tais experiências, assim como a da UBS Boracea e suas equipes da Estratégia Saúde da Família (ESF) 26, pavimentaram o caminho para intervenções futuras, como o DBA. Na região houve também a atuação de uma organização não-governamental (ONG) dedicada à redução de danos, a É de Lei. Surgida para promover a distribuição de insumos a usuários de cocaína injetada, nos anos 1990, começou a se dedicar aos consumidores de crack a partir do ano 2000. Chegou a distribuir, sem sucesso 37, cachimbos de madeira e contou, em 2007, com dois redutores de danos que, uma vez por semana, entre 15:00 e 18:00, percorriam a região e distribuíam preservativos, piteiras de silicone, manteiga de cacau e folhetos sobre a ONG 38. Segundo nossos interlocutores, essa experiência não teve influência na concepção inicial do DBA.

\section{Surge a "favelinha"}

No terceiro trimestre do primeiro ano de governo de Fernando Haddad, em 2013, a administração municipal permitiu a formação de uma concentração de barracos nas proximidades do "fluxo", parte em substituição, parte em acréscimo às antigas malocas de lona que, desde muito, eram precariamente erguidas na Rua Helvetia, nas alamedas Cleveland, Dino Bueno e Barão de Piracicaba, na Praça Júlio Prestes e no Largo Coração de Jesus. A administração municipal deixou de fazer o serviço de retirada das madeiras e outros materiais, permitindo que estes se acumulassem para a confecção de barracos. Nossa interlocutora, Julinha, assistente social lotada na Saúde, testemunhou a corrida em torno da montagem de barracos e a esperança daquelas pessoas de serem incluídas em algum programa de moradia, meses antes da implantação do DBA. Ela conversou conosco na tenda da Rua Helvetia e nos disse: "E aí em setembro começam as barracas! Ninguém tira mais! E aí foi vindo gente de tudo quanto era lugar. Porque a mídia dizia que a prefeitura precisava resolver, fazer alguma coisa. As pessoas acharam que iam ganhar programa aluguel! Quantas e quantas pessoas chegaram aqui e montaram sua barraca acreditando que iam ganhar programa aluguel!".

A "favelinha", como ficou conhecida, também se avolumou por uma dinâmica inerente à vida na rua e às táticas de sobrevivência dos desafortunados 36, que pode ser apresentada em dois aspectos fundamentais: (i) Construir barracos, e até boas malocas, é uma atividade que pode gerar rendimentos variados na rua; e (ii) A Secretaria Municipal de Habitação trabalha com a lógica da desocupação de barracos para a oferta de seus benefícios como bolsa aluguel ou inscrição em programa habitacional.

Nesse contexto, é importante perceber o papel da mídia que, ao divulgar a existência da "favelinha”, gerou uma corrida ao local, inclusive pelo fato de que se estava exibindo o problema na forma de denúncia, o que, em contrapartida, sinalizava a urgência de uma resposta por parte do poder público. Os desafortunados parecem conhecer muito bem o rol de providências disponíveis nesses casos. 


\section{O Grupo Executivo Municipal e a concepção inicial do DBA}

Desde meados dos anos 1990 até a criação do DBA, as ações do poder público na região foram marcadas pela predominância do dispositivo policial e por terem um caráter de ação imediata e pretensamente definitiva, com a intenção de acabar com a Cracolândia. Isso está explícito nas denominações que receberam: Tolerância Zero, Operação Limpa e Operação Dor e Sofrimento. Um importante sinal do caráter diferenciado do DBA foi a criação de um Grupo Executivo Municipal (GEM), em acordo com o programa do governo federal Crack: é Possível Vencer 26, responsável pela concepção e implantação do Programa. O GEM ficou sob a responsabilidade da Área Técnica de Saúde Mental, Álcool e Drogas da SMS. Em primeiro plano, estão, inicialmente, além da SMS, a Secretaria Municipal de Assistência e Desenvolvimento Social (SMADS), a Secretaria Municipal de Direitos Humanos e Cidadania (SMDHC) e a Secretaria Municipal de Segurança Urbana (SMSU). Essa última teve presença decrescente na gestão local do Programa, segundo declarações de técnicos que integraram o DBA desde a sua implantação.

Sobre isso, Julinha, que vivenciou os momentos iniciais de articulação do Programa, afirmou: "A ideia dele [o prefeito] fazer alguma coisa pra Cracolândia já existia com o GEM. Por que que a gente estava aqui desde sempre e essas pessoas vieram pra cá, esses profissionais vieram pra cá pra montar o Braços Abertos em julho [de 2013]? Em dezembro eu já sabia que ia acontecer alguma coisa, muito por baixo dos panos. E aí o que a gente fez? 'Converse com as lideranças! Converse com as lideranças!'. Reivindicaram moradia, trabalho, alimentação, estudo! Eu vi o prefeito esperando essas pessoas no gabinete e os carros vindo buscar essas pessoas para ir conversar com o prefeito".

A nova administração municipal tomou posse em janeiro de 2013. Em maio do mesmo ano, técnicos da prefeitura circulavam pela Cracolândia com a finalidade de levantar o que deveria ser feito e como se agiria no local. As reuniões no gabinete do prefeito se incorporaram às histórias contadas na Cracolândia a respeito do surgimento do DBA. Os moradores do local, que haviam participado dessas conversas, gostavam de recordar detalhes e de sublinhar o quanto tal ou qual característica do Programa havia se originado de uma sugestão sua.

"Quem inventou o Braços Abertos fui eu", escutamos esta frase ao conversar com um beneficiário do DBA. Tratava-se de um usuário de crack de trato razoavelmente difícil, pois às vezes mostrava-se violento, mas orgulhava-se de ter participado das reuniões preparatórias com o prefeito Fernando Haddad para a implantação do DBA.

Para elaborar a nova política e dar início ao Programa, o prefeito Fernando Haddad fez, durante o ano de 2013, diversas visitas informais à Cracolândia e estabeleceu vínculo com alguns usuários de crack e lideranças, como o usuário autor da frase "Quem inventou o Braços Abertos fui eu". A partir dessas conversas informais foi se desenhando um grupo de lideranças que passou a ser convidado a auxiliar na definição e planejamento das ações do Programa ${ }^{39}$. Inclusive, a incorporação da Secretaria Municipal do Desenvolvimento, Trabalho e Empreendedorismo (SMDTE) ao GEM foi fruto dessas reuniões com os frequentadores da Cracolândia.

Em seu início, a Rede de Atenção Psicossocial (RAPS) em torno do DBA era composta por dois Centros de Atenção Psicossocial Álcool e Drogas - CAPS AD III - (Centro e Complexo Prates), um CAPS Adulto, um CAPS Infantil e o CAPS instalado nas dependências do Centro de Referência de Álcool, Tabaco e Outras Drogas (CRATOD). Na verdade, a integração dos serviços municipais com o estadual fez parte de um processo anterior, que envolveu anos de entendimentos entre os profissionais das duas esferas de governo voltadas à construção da RAPS naquele território e, também, em outros. Na prática, isso significava que, apesar do município e do estado desejarem referenciar seu atendimento em equipamentos próprios, em caso de necessidade eles utilizariam os serviços uns dos outros - o estado mais voltado às internações em Comunidades Terapêuticas (CT) e a prefeitura trabalhando com os CAPS.

Dos CAPS municipais sairiam os profissionais para compor as equipes de CAPS na Rua, somados a outro equipamento localizado no bairro da Vila Mariana, centro-sul da cidade, mas que trabalhavam na região central, ligados ao Projeto Quixote, especializado no atendimento infantil. O engajamento por parte dos funcionários municipais, com experiência prévia na região, foi positivo, à semelhança do que ocorreu na implantação de equipamentos voltados à redução de danos em usuários de crack em Paris (França) 40,41. 


\section{A transferência da "favelinha" para os hotéis}

Apesar do DBA ter sido um programa com a presença muito forte da Saúde Mental da prefeitura, os procedimentos padrões e as competências institucionalizadas na administração municipal permaneciam. O cadastro dos futuros beneficiários, por exemplo, era realizado por um pessoal contratado pela SMADS, secretaria usualmente responsável por cadastrar pessoas em situação de rua. Para tanto, semanas antes do início do Programa, ocorreu a contratação de agentes sociais que viriam a ser a primeira turma de agentes sociais do DBA. Os trabalhadores lotados na SMS, mesmo quando assistentes sociais, ficaram de alguma forma alijados de certas responsabilidades, apesar da sua experiência naquele território.

Contudo, no campo e sujeitos às urgências impostas por aquele tipo de trabalho, os profissionais mais experientes acabaram por servir de guia para os novos contratados, garantindo-lhes o trânsito no local. Desse modo, a presença pregressa das equipes do Consultório na Rua avalizou e garantiu a entrada dos novos trabalhadores sociais, da SMADS, contratados pela Sociedade Amiga e Esportiva do Jardim Copacabana (SAEC). Posteriormente, com o desenvolvimento do DBA, o SAE iria servir de ponto de apoio para as equipes do Consultório na Rua da SMS. A assistente social, Arlene, que desde 2010 estava alocada no SAE da Alameda Cleveland, um equipamento da SMS ao lado do "fluxo", destaca essa mediação: "Então eles foram fazendo isso. A Saúde, por vínculo com a população aqui, para essas pessoas que entraram agora na SAEC e na assistência não serem agredidos nem nada, estava junto para mostrar: 'ó a gente está aqui, está com eles viu, pode ficar tranquilo que a gente está aqui junto'. Então a Saúde só foi fazendo isso: a segurança dos novos trabalhadores da assistência".

As práticas dos vários sujeitos envolvidos podem ser compreendidas, com base em suas múltiplas relações de poder, em um cenário complexo, ao se evidenciar a dimensão da agência 42 nas relações entre usuários e moradores com o corpo técnico municipal. Assim se evidenciam discursos e práticas que assentam processos de acomodamento de pessoas por uma certa "pedagogia da conversão" 43, dedicando-se a transformar "sujeitos ingovernáveis" em sujeitos legais do estado.

Como já assinalamos, em meados de 2013 a prefeitura tinha instalado um novo equipamento na Rua Helvetia, o Centro Integrado de Reinserção Social de Braços Abertos, também chamado de Ponto de Apoio. Porém, a resposta definitiva do município à "favelinha" viria em uma quarta-feira, 15 de janeiro de 2014: o DBA transferiu pouco mais de 300 pessoas que residiam nos barracos da Rua Helvetia e Alameda Dino Bueno, próximos da Estação Júlio Prestes, ocupados, em sua maioria, por consumidores de crack, para hotéis do entorno. Esses indivíduos deixavam de dormir na rua e passavam a ser hóspedes.

Algumas semanas após o início do Programa, os gestores do Programa Operação Trabalho (POT), ainda sob a responsabilidade da ONG Brasil Gigante, e técnicos do município ligados à SMS e à SMADS fizeram uma reunião, da qual participamos, para estabelecerem procedimentos destinados ao acompanhamento do cotidiano dos beneficiários, visando a estimular sua participação no Programa e para dar respostas às demandas que surgissem. Esses procedimentos consistiram no que expomos a seguir.

Após despertarem e deixarem o hotel, os beneficiários se dirigiriam ao restaurante Bom Prato, localizado na Rua Dino Bueno, para o café da manhã. Seu ingresso no restaurante seria possibilitado por um crachá, fornecido pelo orientador social a cada um de seu grupo de vinte beneficiários. Raramente a equipe estava completa e os faltantes eram objeto de busca ativa por parte dos 44 orientadores socioeducativos da SMADS e dos agentes comunitários de saúde da SMS. As informações sobre a falta ao trabalho, para a posterior busca ativa, eram obtidas por aqueles profissionais após o café da manhã, no local de saída das equipes. Em seguida, os agentes sociais da SMADS e agentes comunitários de saúde, responsáveis por cada grupo de beneficiários, iam aos hotéis para encontrá-los e verificar os motivos da falta à frente de trabalho. Entre as 13:00 e 14:00, o trio composto pelos agentes sociais da SMADS, agentes comunitários de saúde da SMS e orientadores sociais da SMDTE reunia-se para debater as diferentes demandas que surgiam. Essa rotina passou a ser praticada pouco mais de um mês após o início dos serviços de zeladoria feitos por parte dos beneficiários. Isso evidencia um esforço no sentido da normalização 42 dos usuários de crack, o que não impede que exista um engajamento prático dos sujeitos. Nas palavras de um beneficiário do DBA de nome Honório: "É o negócio com o 
compromisso, né! Não é compromisso com o Programa, é compromisso consigo próprio. O que eu pego nos pés dos caras é isso".

O hotel é o local onde agentes comunitários de saúde realizam a busca ativa aos beneficiários que possam se encontrar em dificuldade para participar devidamente do trabalho de zeladoria, seja devido a problemas de saúde física ou mental, seja por outro motivo qualquer. Todo hotel tinha um agente de saúde que fazia um acompanhamento estrito da medicação dos beneficiários sob tratamento. Quando solicitado, o médico, postado regularmente na tenda do DBA, realizava atendimentos nos quartos, que também poderiam receber a visita de outros profissionais como psicólogos e enfermeiros. Sem qualquer exigência relativa à abstinência do consumo do crack, procedimento condizente com as práticas de redução de danos e diversa da política de internação do Programa Recomeço 44, da gestão estadual.

\section{A nova "favelinha"}

A diversificação do consumo de bens e serviços por parte dos beneficiários do DBA em relação ao estado anterior sob a ditadura do "corre", esta "verdadeira maratona diária em busca de fundos para o consumo de crack, por meio muitas vezes de atividades com razoável grau de periculosidade como a prostituição e os pequenos furtos" 45 (p. 231), parece ser mais um dos aspectos centrais nas mudanças por que passam essas pessoas ao aderirem ao programa municipal que para Antônio Lancetti 26 era baseado no housing first. Para esse importante psicanalista e um dos idealizadores do DBA, além das vagas em hotéis se impunha uma nova temporalidade que se afasta do imediatismo, regida pela perspectiva de pagamento semanal.

Apesar disso, uma acusação constante feita ao DBA é a de que o Programa visaria à expulsão dos usuários de crack do bairro da Luz para valorizar os imóveis adquiridos pela empresa Porto Seguro. No entanto, a localização dos hotéis que passaram a abrigar os beneficiários do DBA, perto do "fluxo", indicava o contrário. Reforçando esse ponto, temos a fala de Amanda, uma socióloga e funcionária de carreira da prefeitura com mais de uma década de dedicação ao trabalho social na Cracolândia e que, consequentemente, havia lidado com algumas das políticas públicas implantadas no território. Disse ela, em 2013, ano em que a entrevistamos pela primeira vez, que o DBA trazia algo de inovador com relação aos interesses do capital imobiliário: "Viu, esse aspecto de as pessoas serem tratadas aqui, acolhidas aqui, isso é revolucionário! Principalmente pra quem critica que tem o aspecto só da especulação imobiliária. Isso é mentira pura, porque se fosse só essa ideia, jamais alugariam hotéis aqui”.

De qualquer forma, embora uma nova atmosfera tomasse conta da região, não se conseguiu superar o maior problema relacionado à proibição do crack: o tráfico e suas estratégias de comercialização. Por exemplo, uma das mais impactantes ações do Primeiro Comando da Capital (PCC), uma organização criminosa, que também comanda boa parte do tráfico de drogas no estado, foi a construção de malocas de lona para armazenar e acobertar o comércio de drogas na Cracolândia. O problema é que o DBA havia surgido com o desmonte dos barracos de madeira existentes e a transferência de seus moradores para hotéis próximos ao "fluxo", dado que esta proximidade foi uma condição imposta pelos usuários de crack para aderirem massivamente ao Programa. Então, a não existência de barracos acabou se tornando o limite político inicial do DBA ${ }^{39}$ que, para ingresso e permanência no Programa, mantinha um nível de baixa exigência 26.

Um dos locais em que as malocas chegaram a ser montadas foi na praça construída na esquina da Rua Helvetia e Alameda Cleveland, dispondo de aproximadamente $300 \mathrm{~m}^{2}$ de terreno e dotada de floreiras e bancos. Esse trecho chegou a abrigar 500 pessoas, numa configuração que a mídia chamou novamente de favelinha. Mais do que isso, começaram as acusações de que, em alguma medida, a administração municipal era leniente com o tráfico de drogas e com o PCC, por permitir a existência de malocas ocupadas por traficantes. A prefeitura, então, retirava as malocas, mas era obrigada a lidar com ingerências por parte de agentes do governo estadual. Em uma desocupação da favelinha, um policial civil foi flagrado pelos frequentadores da Cracolândia quando filmava uma ação no terreno. O fato gerou revolta e a reação do policial foi disparar duas vezes contra o solo, ferindo dois cidadãos que ali faziam uso de crack. Uma revolta ocorreu e a Tropa de Choque da Polícia Militar interveio com violência.

Como o DBA, desde seu início, viu-se sob fogo cruzado, particularmente por remunerar o trabalho dos beneficiários sem exigir abstinência, o que foi rotulado como "bolsa crack", termo pejorativo 
que havia sido criado em referência ao Cartão Recomeço, lançado pelo governo estadual para financiar internações em CT. O pretenso incentivo municipal ao uso de drogas era, por consequência, visto como estímulo ao tráfico de drogas. Nesse contexto hostil, a própria ONG gestora dos contratos com os hotéis e responsável pelo pagamento dos beneficiários foi acusada de pagar traficantes com a verba recebida pela prefeitura. Tais acusações serviram para minar as ações do DBA.

\section{O fim do DBA}

Quando teve início o governo de João Dória, havia um clamor midiático por mudanças na Cracolândia. Prevendo uma onda de repressão ao "fluxo", os militantes da Craco Resiste organizaram uma vigília noturna no dia 2 de janeiro de 2017. Eram profissionais que conheciam a história das pessoas que frequentavam o "fluxo" e com quem estabeleceram vínculos, conquistaram algum grau de confiança, cumplicidade e amizade. Naquele momento, a sensação era de que a presença de trabalhadores sociais e da saúde, no território, era uma garantia de que haveria resistência às investidas mais violentas por parte da polícia, ou seja, de que haveria questionamentos e o devido acompanhamento de qualquer prisão arbitrária.

Em 21 de maio de 2017, numa megaoperação que envolveu 900 agentes numa ação açodada e descoordenada, a polícia invadiu a Cracolândia com o objetivo de prender traficantes e limpar a área. Muito próximo da cena de uso aconteciam atividades da Virada Cultural, um megaevento da prefeitura, com 24 horas de duração. O poder municipal havia deixado de recolher o lixo do "fluxo" dez dias antes da operação, produzindo ali uma montanha imensa de dejetos de todos os tipos. Ao acompanhar a ação, o prefeito João Dória anunciou o fim do DBA, que foi associado à montanha de lixo e ao volume de traficantes presos com armamento pesado. Mais do que isso, o prefeito declarou o fim da própria Cracolândia e o lançamento de uma proposta de revitalização da região.

Em entrevistas por nós realizadas entre funcionários da prefeitura, pudemos verificar que, como a operação foi sigilosa, apenas os órgãos de segurança haviam sido envolvidos em sua preparação. Portanto, as secretarias municipais de assistência e saúde só foram comunicadas na data da ação policial na Cracolândia. A ação ocorreu sob o comando de membros do aparato de segurança, com a estrutura fornecida pelo governo estadual (gestão Geraldo Alckmin - PSDB). A história parecia se repetir, pois também em 2012, numa ação repressiva da prefeitura naquela região, a secretária de assistência social foi a última a saber da intervenção 39. Desse modo, em maio de 2017, o DBA encerrou suas atividades, chegando ao fim uma política pública focada na redução de danos, talvez uma das mais audaciosas do país.

\section{Considerações finais}

A construção e o desmantelamento do DBA nos conta a história de nascimento, vida e morte de uma política pública 19,20,21. Uma política pública única que logrou ser construída sobre as bases do trabalho pregresso de profissionais, principalmente, do campo da Saúde e, em específico, da Saúde Mental. Profissionais esses que não pertenciam somente ao quadro estável do serviço público municipal, mas que também incluía contratados pelo município e que vinham atuando na Cracolândia ao menos nos cinco anos que precederam o início do Programa. Essa experiência acumulada deu origem a uma política pública com caráter participativo e contratual na sua elaboração e gestão. Ao terem oportunidade de elaborar, implantar e gerenciar um programa abrangente no atendimento público aos frequentadores da Cracolândia, esses técnicos atuaram sob a égide da intersetorialidade, o que significou o envolvimento de um número significativo de secretarias municipais. Tal característica influenciou o modo como o DBA lidou com os conflitos mais relevantes, como os casos das "favelinhas", assim como levou à implantação de novas ideias, como a contratação dos hotéis e a oferta de postos de trabalho como meio de se auferir renda.

A história de vida do Programa assinala a potência de políticas que surgem em relações íntimas com seu ambiente e evoluem de maneira adaptativa. O DBA teve de acomodar-se à presença sempre conflituosa do crime organizado e das polícias na Cracolândia 10,11,12. De fato, essa foi uma dificuldade que essa política teve de enfrentar e que acabou por influenciar, de modo significativo, seu cotidiano, 
desde a sua instalação até o encerramento. Os profissionais participantes tiveram de desenvolver competências específicas para lidar com as ações violentas periódicas que sempre mantiveram o Programa na berlinda.

O esfacelamento do DBA mostrou, num quadro comparativo com as situações anteriores e o contexto atual, que o Programa deixou uma importante herança, no que se refere à luta pela inclusão de grupos marginalizados, em situação de fragilidade social. Pudemos observar o surgimento de uma militância em prol dos direitos recém-adquiridos pelos usuários de crack, o que certamente poderá significar alguma resistência contra medidas do poder público que não levem em consideração essa nova realidade de engajamento pela cidadania, assim como gerar avanços em novas políticas voltadas a essa população num futuro próximo.

\section{Colaboradores}

Y. D. D. Alves elaborou o trabalho (pesquisa de campo e bibliográfica), revisou criticamente e participou da aprovação final da versão a ser publicada. P. P. G. Pereira contribuiu substancialmente para a concepção do trabalho, a aquisição, análise e interpretação de dados, revisou criticamente e participou da aprovação final da versão a ser publicada. $P$. S. Peres revisou criticamente o trabalho com conteúdo intelectual importante, aprovou a versão final a ser publicada.

\section{Informações adicionais}

ORCID: Ygor Diego Delgado Alves (0000-00026730-3255); Pedro Paulo Gomes Pereira (00000002-0298-2138); Paulo Sergio Peres (0000-00023880-4261).

\section{Agradecimentos}

A pesquisa foi desenvolvida com o apoio da Coordenação de Aperfeiçoamento de Pessoal de Nível Superior (Capes) e da Fundação de Amparo à Pesquisa do Estado de São Paulo (FAPESP).

\section{Referências}

1. Brewer G, DeLeon P. The foundations of policy analysis. Pacific Grove: Brooks and Cole; 1983.

2. Bridgman P, Davis G. What use is a policy cycle? Plenty, if the aim is clear. Australian Journal of Public Administration 2003; 62:98-102.

3. Denhardt R, Grubbs J. Public administration: an action orientation. Belmont: Thompson; 2003.

4. Jansen MWJ, van Oers HAM, Kok G, de Vries NK. Public health: disconnections between policy, practice and research. Health Res Policy Syst 2010; 8:37.

5. Patton C, Sawicki D. Basic methods of policy analysis and planning. Upper Saddle River: Prentice-Hall; 1993.

6. Moran M, Rein M, Goodin R. The Oxford handbook of public policy. Oxford: Oxford University Press; 2008.

7. Brandão B, Carvalho J. Programa De Braços Abertos e as políticas de drogas na sociedade de controle. Outros Tempos 2017; 14:184-206.

8. Trinta DRF. O fim da Cracolândia: etnografia de uma aporia urbana [Dissertação de Mestrado]. Campinas: Universidade Estadual de Campinas; 2017.

9. Mingardi G, Goulart S. As drogas ilícitas em São Paulo: o caso da Cracolândia. São Paulo: Instituto Latino-americano das Nações Unidas para Prevenção do Delito e Tratamento do Delinquente; 2001. (Coleção Revista ILANUD, 15).

10. Rui T, Fiore M, Tofoli LF. Histórias miúdas da criminalização das drogas e das vidas: sobre alguns beneficiários do De Braços Abertos. Boletim IBCCRIM 2016; (286):17-9.

11. Adorno R. Etnografia da Cracolândia: notas sobre uma pesquisa em território urbano. Saúde Transform Soc 2013; 4:4-13.

12. Da Silva $S$, Adorno R. A etnografia e o trânsito das vulnerabilidades em territórios de resistências, registros, narrativas e reflexões a partir da Cracolândia. Saúde Transform Soc 2013; 4:21-31. 
13. Costa J. A internação compulsória dos viciados em crack a partir da ponderação entre liberdade e dignidade humana. Juris Poiesis 2013; 16:27-51.

14. Frúgoli Jr. H, Cavalcanti M. Territorialidades da(s) cracolândia(s) em São Paulo e no Rio de Janeiro. Anuário Antropológico 2013; 2:73-97.

15. Rui T. Amarga delícia: experiências de consumo de crack na região central de São Paulo. Inter-Legere 2014; 15:87-109.

16. Raupp L, Adorno R. Uso de crack na cidade de São Paulo/Brasil. Toxicodependências 2010; 16:29-37.

17. Aderaldo G, Fazzioni N. Choro e samba na Luz: etnografia de práticas de lazer e trabalho na R. Gal. Osório. Ponto Urbe 2012; (11). http://journals.openedition.org/pontour be/1159.

18. Calil T. Relatos e imagens da Cracolândia: modos de vida e resistência na rua. Cadernos de Arte e Antropologia 2016; 5:91-102.

19. Faria CAP. Ideias, conhecimento e políticas públicas: um inventário sucinto das principais vertentes analíticas recentes. Rev Bras Ciênc Soc 2003; 18:21-9.

20. Frey K. Políticas públicas: um debate conceitual e reflexões referentes à prática da análise de políticas públicas no Brasil. Planej Polít Públicas 2000; 21:211-59.

21. Reis E. Reflexões leigas para a formulação de uma agenda de pesquisa em políticas públicas. Rev Bras Ciênc Soc 2003; 18:11-4.

22. Abélès M. Pour une anthropologie des institutions. L'Homme 1995; (135):65-85.

23. Miranda M, Beraldo de Oliveira M, Ferreira Paes V. Antropologia e políticas públicas: notas sobre a avaliação do trabalho policial. Cuadernos de Antropología Social 2007; 25:51-70.

24. Bernard H. Participant observation. In: Bernard H, editor. Research methods in anthropology: qualitative and quantitative approaches. 4th Ed. New York: Altamira; 2008. p. 342-86.

25. Clemente M. Cracolândia dia a dia. São Paulo: Giostri; 2016.

26. Lancetti A. Contrafissura e plasticidade psíquica. São Paulo: Editora Hucitec; 2015.

27. Maiorki G, Dallabrida V. A indicação geográfica de produtos: um estudo sobre sua contribuição econômica no desenvolvimento territorial. In: Dallarida V, organizador. Indicação geográfica e desenvolvimento territorial: reflexões sobre o tema e potencialidades no Estado de Santa Catarina. São Paulo: LiberArs; 2015. p. 13-25.

28. Queiroz J. Corruption: can Brazil win this war? [Masters' Thesis] Bergen: The University of Bergen; 2015.

29. Domingos R. São Paulo fashion district: modelos de parcerias para viabilizar um polo criativo de moda em São Paulo [Monografia]. São Paulo: Escola de Administração de Empresas de São Paulo, Fundação Getulio Vargas; 2015.

30. Nasser MMS. Cracolândia como campo de gravitação. Ponto Urbe 2017; (21). http://jour nals.openedition.org/pontourbe/3530.
31. Santos C. A situação do crack na cidade de São Paulo [Monografia de Especialização]. Curitiba: Universidade Tecnológica Federal do Paraná; 2011.

32. Arruda M. A Cracolândia muito além do crack [Tese de Doutorado]. São Paulo: Escola de Enfermagem, Universidade de São Paulo; 2014.

33. Elias N, Kamnitzer P. La dynamique de l'Occident. Paris: Pocket; 2007.

34. Waranda V. Liminaridade, bebidas alcoólicas e outras drogas: funções e significados entre moradores de rua [Tese de Doutorado]. São Paulo: Universidade de São Paulo; 2009.

35. Oliveira N. A intervenção policial na Cracolândia e a concepção integrada de justiça de Nancy Fraser [Monografia]. Juiz de Fora: Faculdade de Direito, Universidade Federal de Juiz de Fora; 2012.

36. Anderson L, Snow D. Desafortunados: um estudo sobre o povo da rua. Petrópolis: Editora Vozes; 1998

37. Domanico A. Craqueiros e cracados: bem-vindo ao mundo dos nóias! Estudo sobre a implementação de estratégias de redução de danos para usuários de crack nos cinco projetos-piloto do Brasil [Tese de Doutorado]. Salvador: Universidade Federal da Bahia; 2006.

38. Frúgoli Jr. H, Sklair J. O bairro da Luz em São Paulo: questões antropológicas sobre o fenômeno da gentrification. Cuadernos de Antropología Social 2009; (30):119-36.

39. Alves Y. Jamais fomos zumbis: contexto social e craqueiros na cidade de São Paulo. Salvador: EDUFBA; 2017.

40. Jauffret-Roustide M, Cailbault I. Drug consumption rooms: comparing times, spaces and actors in issues of social acceptability in French public debate. Int J Drug Policy 2018; 56:208-17.

41. Cleirec G, Fortias M, Bloch V, Clergue-Duval V, Bellivier F, Dusouchet T, et al. Opinion of health professionals and drug users before the forthcoming opening of the first drug consumption room in Paris: a quantitative crosssectional study. Harm Reduct J 2018; 15:53.

42. Mahmood S. Teoria feminista, agência e sujeito liberatório: algumas reflexões sobre o revivalismo islâmico no Egipto. Etnográfica 2006; 10:121-58

43. Das V, Poole D. El estado y sus márgenes. Etnografías comparadas. Revista Acadèmica de Relaciones Internacionales 2008; (8). https:// revistas.uam.es/index.php/relacionesinterna cionales/article/download/4916/5381.

44. Menezes LF. Entre a saúde e a repressão - políticas públicas na região da Cracolândia - SP [Dissertação de Mestrado]. São Paulo: Faculdade de Saúde Pública, Universidade de São Paulo; 2016.

45. Alves Y. Jamais fomos zumbis: contexto social e craqueiros na cidade de São Paulo [Tese de Doutorado]. Salvador: Universidade Federal da Bahia; 2015. 


\section{Abstract}

Public policies for the crack cocaine scene known as Crackland (São Paulo, Brazil) have been implemented for decades, but there has been no comprehensive description of such policies. We conducted this study due to the importance and innovative nature of the Open Arms program, in order to provide a comprehensive picture of the program, from its beginning until it was closed down. The description involves: (i) a survey of the activities developed by public agents who preceded the program and who directly influenced its formulation; (ii) a description of the status of Crackland when Open Arms was launched; (iii) specification of the institutional actors and their respective roles; and (iv) an explanation of the main events marking this public policy's development until its extinction. We drew on our ethnographic experience at Crackland, comparable to an important share of the literature on this topic. We identified strong influence from prior work by the professional staff, especially in the field of mental health in the municipal government in designing and developing the Open Arms program; however, the program developed with active participation by various entities, with important collaboration between municipal departments and agencies. The study revealed a close and adaptive relationship between the program and the Crackland scene, as well as clashes with organized crime and the police, requiring the development of specific skills by the municipal agents. When the program was dismantled, it left an important legacy with the emergence of activism in defense of the rights recently acquired by crack users, which should certainly play out in the form of some resistance to government measures.

Crack Cocaine; Ethnography; Public Policy

\section{Resumen}

Las políticas públicas dirigidas a Cracolandia (São Paulo, Brasil) se han implementado hace décadas y carecen de una descripción amplia. Realizamos este estudio por la importancia y carácter innovador del programa De Brazos Abiertos (DBA), con el propósito de ofrecer un cuadro comprensivo desde su inicio hasta su desmantelamiento. A través de: (i) la relación de las actividades desarrolladas por agentes públicos que precedieron el programa y que influenciaron directamente en su formulación; (ii) la descripción del estado en el que se encontraba Cracolandia en el momento de la implantación del DBA; (iii) la especificación de los actores institucionales y sus atribuciones; (iv) la exposición de los principales acontecimientos que marcaron el desarrollo de esta política pública hasta su extinción. Para tal fin, nos valemos de nuestra vivencia etnográfica en Cracolandia, que puede ser cotejada con una parte importante del material bibliográfico existente sobre el tema. Identificamos una fuerte influencia del trabajo anterior de profesionales, principalmente procedentes del campo de la salud mental en el municipio tanto en la concepción, como en el desarrollo del DBA; pese a que hubo participación activa de diversos entes, con una importante interrelación. La investigación mostró la relación íntima y adaptativa entre el programa y el ambiente de Cracolandia, así como conflictos con el crimen organizado y organismos que fomentaron el desarrollo de competencias específicas por parte de los agentes del municipio. Al ser desmantelado, el programa dejó una importante herencia en el surgimiento de una militancia en pro de los derechos recién adquiridos por los consumidores de crack, lo que ciertamente podría significar alguna resistencia contra las medidas del poder público.

Cocaína Crack; Etnografía; Política Pública
Recebido em 04/Dez/2018

Versão final reapresentada em 26/Abr/2019

Aprovado em 28/Ago/2019 